\title{
Personalized Reading: Developing User-Describing Profile for Slow Learner Children
}

\author{
https://doi.org/10.3991/ijim.v13i07.10775 \\ Marzita Mansor ${ }^{(\bowtie)}$ \\ Universiti Pendidikan Sultan Idris, Tanjung Malim, Malaysia \\ marzita@fskik.upsi.edu.my \\ Wan Adilah Wan Adnan, Natrah Abdullah \\ Universiti Teknologi MARA, Shaha Alam, Malaysia
}

\begin{abstract}
Personalization is a good supplement for learning process. It has been claimed that personalization has a huge potential of providing solution to facilitate the learning path based on children ability and preferences. Diverse research on personalized learning for children have been conducted which, are commonly concerns on the development and implementation of personalized learning products and services. However these researches have little emphasized in exploring slow learner personalized learning process particularly on their reading ability. With that, this paper aims to highlight two key important processes of personalization for slow learner children which are construction of user profile and scenario. The scope of this study is on personalization of reading for slow learner children. There were 13 slow learner children with reading difficulties from primary school participated in this study. The key findings from this study are the construction of user profile and scenario that represent the personalization for reading. These user profile and scenario construction then provide guidelines for the development of personalized interface design for slow learner reading application.
\end{abstract}

Keywords-Personalized Reading, User Profile, Scenario, Slow Learner

\section{Introduction}

There are tremendous changes on how children learn and how knowledge is delivered. The changes can be attributed to the extensive use of the technology that knowledge is accessible anytime anywhere. However, there is limited research that examines the effectiveness of the technology that assists delivering knowledge to learners, especially children who are slow learners and require special attention. The first consideration is to understand the whole pictures of the slow learners and the second consideration is to determine the best approach of using technology to tackle the root of the problem. Difficulties in reading is identified as the leading problem related to literacy among slow learners. Difficulty in reading will negatively influence their academic performance at school. 
Personalization is identified as the best solution. It is capable of providing a personalized approach based on the reading ability and preferences of the slow learners. There is a minimal discussion in the literature of user profile as a personalization process, especially for the children who are slow learners. However, it is debatable that the user profile construction plays a vital role in personalization. [1] indicate that there are three (3) main directions in the development of personalization. These three directions are similar to the current study which encompass understanding the student's personality (user profile) and personalization approach as a feasible solution. [2] mutually agreed with the fact the knowledge on the user provides a better approach to personalization. This paper describes the personalization processes which is important as it leads to the development of personalized interface design. The identified processes is the construction of slow learner profile which describe the information of the slow learners. As the development process of the user profiles requires a deeper understanding of slow learner's explicit and implicit information, several steps are provided to develop the slow learner profiles to cater to both information by employing qualitative approach in the data collection process. With that, this paper aims to highlight a key important processes of personalization for slow learning-children which is the construction of user profile as it is provides step by step guidelines to the successful personalization. Section 2 of this paper discusses the related literature review while describes the methodology of the study. Section 4 present a detailed explanation of the key process of personalization which is the construction of the slow learner profile. Finally, Section 5 concludes the study.

\section{$2 \quad$ Literature Review}

The last decades has witnessed significant changes in education due to the enhancement in educational technology that has provided opportunities for all learners to learn any time. These advancements and increased use of technology are popularised the shift from the traditional one-fits-all approach to a personalized experience. Personalization technology is a powerful tools in enhancing user experience, yet simultaneously provide a personalization tool that meets the needs, preferences and knowledge of users. The personalization technology also promises a high potential that enables a technological tool to be accessible by users according to individual requirement by providing a solution to facilitate the expression of user needs [3]; [4]. However, looking at the personalization as a technological solution is inadequate. The concept of personalization is more than a simple process of providing personalized services based on gathered and observed activities. Research on personalization has demonstrated that personalization provides a broad view by changing human lives.in education, personalization is found to be a good supplement for the learning process.

Not only that, personalization has been widely applied in several areas such as elearning, adaptive learning and web [5]; [6];[7];[8]. Various studies have attempted to utilised personalization as a tool for learning [9]. For example, [10] provide personalisation in searching information in the digital library, personalisation of a storybook to improve distance communication by [11], and personalisation of learning algebra by 
[12]. Although technology has significantly impacted society and is ubiquitous at all levels of education, some categories of people in need are unfortunately left behind. The minority category focused on this study is slow learner children. In general, they are the minority of students who struggle with literacy problem, especially reading. Their existence in primary school is considered one of the biggest challenges that school teachers face nowadays, especially in order to achieve the school's aim of producing zero illiteracy among students. Zero illiteracy explains that every child at the school must be able to perform basic literacy skills including reading, writing, and calculating. Ensuring basic literacy seems like an easy task, but requires excellent and thorough planning. The implementation of zero illiteracy programmes might be possible for normal children, but teaching all children to read in school is a challenging process [7]. One of the challenges pertains the way to ensure all children who have reading difficulties, including slow learners allocated at normal classroom setting in primary school, have the ability to read like normal children. One of the ways to help slow learner children is by fully understanding them and by providing a better tool that can assist them to read better. Although personalisation has been identified as a better approach in learning, a growth in personalisation studies that present personalisation as just a product was identified. Adamantly, limited studies have focused on the understanding process of the unique profile of the users and describing how the process of the personalisation is implemented from sketch to the end product. A detailed understanding of user profile leads to a better design of the personalised materials. User profile is important for personalised information access. [13] presented that user profile provides several ways on building, managing, and representing information personalised for each user.

\section{Methodology}

User profiling can be defined as the data identification process of a user's interest domain [14]. Realising the criticality using user profile to understand slow learners, this paper presents how a concept-based user profile technique is used to develop a user-describing profile. This work also adapts the user profile development methodologies by [15] which build user profiling based on the type of users' information, either explicit or implicit information. A similar approach using explicit user feedback and implicit user feedback was also explored by [16] and [15]. The user profile and developed scenario are vital in determining the personalisation features in the personalised interface design. These two elements supplement each other in ensuring that all user needs are well-translated in the form of understandable step-by-step personalised design. In this study, the researchers' present personalisation as one of the supplements embedded in the reading materials to assist slow learners to overcome their reading difficulties. The slow learner children are selected as users due to the reading problem that the slow learner children faced in primary school. Although the data from 13 slow learner children were collected qualitatively, only one user profile and one scenario presented are in this paper to provide a better understanding of how the personalisation process was carried out. Two methods of user construction techniques 
are employed in this study to cater to two types of information of the user, namely, explicit and implicit information. These two methods are explicit user information collection methodologies, often called explicit user feedback and implicit user information collection methodologies, also known as implicit user feedback. These two techniques are important in the construction of user profiling construction where explicit and implicit information of users are incorporated. Fig.1. depicts the several steps required in implementing these two methodologies of user profile construction which are the explicit user feedback and the implicit user feedback:

- Information collection process

- Construction of user profile

- Use of user profile in the application

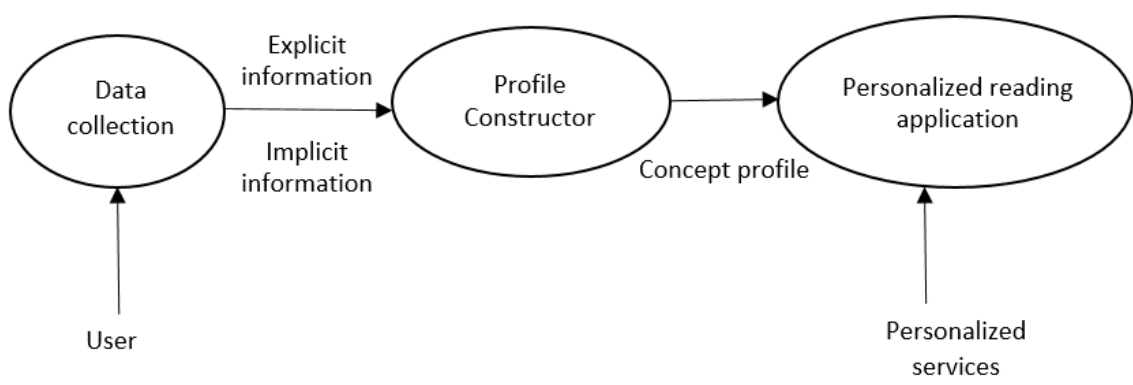

Fig. 1. Overview of user profile concept-based personalization. Adapted by [13]

The framework of our proposed approach is illustrated in Figure 2. 


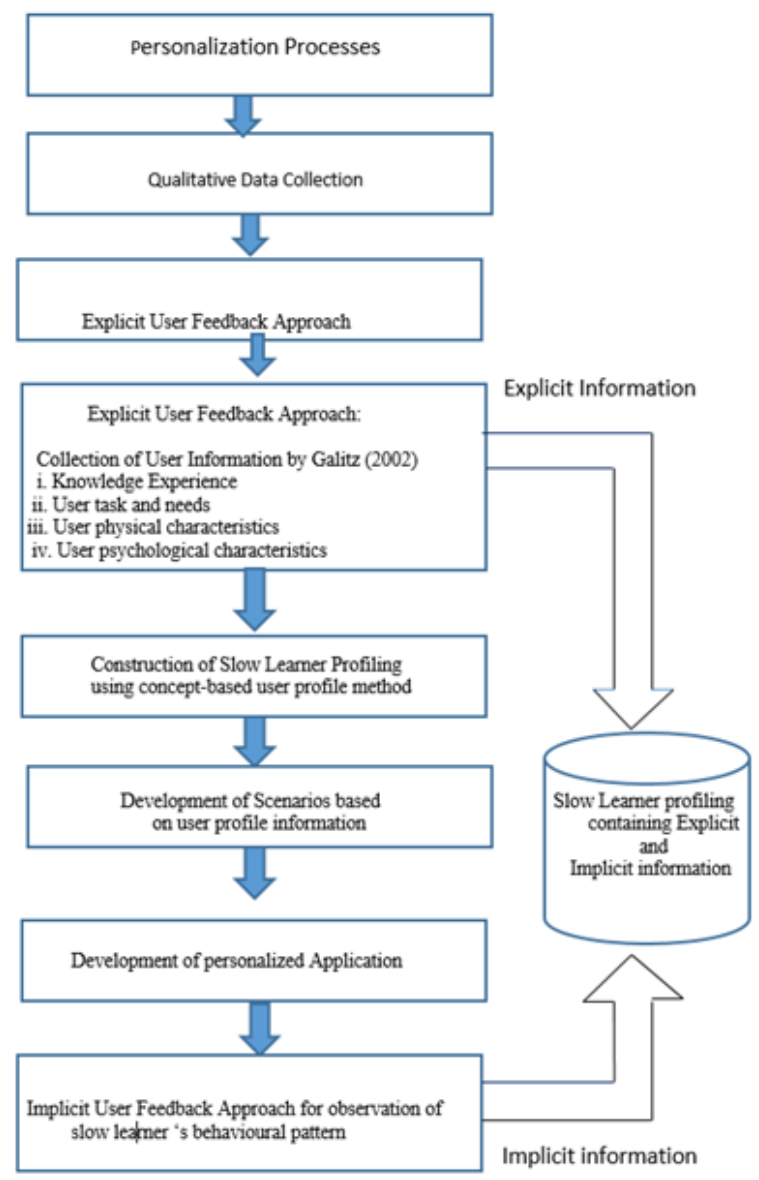

Fig. 2. Personalization process

\subsection{Collecting explicit and implicit information of slow learner}

The collection of information using explicit user feedback and implicit user feedback involves different activities. The explicit user feedback approach requires the researcher to collect information directly from the intended users. The explicit user feedback approach relies on the user's input, thus, explicit information gathered in this process requires direct communication with the user. Particularly, in this research, three (3) main activities are utilised to gather information which are interview, observation, and data analysis. Meanwhile, the implicit user feedback approach gathers implicit information of the user by analysing the information when the user is performing an activity while using the personalised application. To clarify, the total number of respondents involved in this study is 13 slow learner children and one remedial teacher who manages the children in their remedial class. 
Collecting explicit information of slow learner through a qualitative research approach: Different user profile construction technique is utilised based on the type of user information. In this study, the explicit information of the user is collected by gathering the required information in a primary school setting. Personalisation of content is described in this paper due to the importance of identifying the right reading content material for the slow learner children who have difficulties in reading. Hence, a qualitative approach was conducted to collect the explicit information of reading performance of the slow learner children (prior knowledge in reading), reading needs, reading preferences as well as personal information of each slow learner child in order to identify suitable content for personalisation. All the gathered information is essential as provides an in-depth understanding of the real factors that contribute to the reading difficulties and to identify specific needs and preferences of each child for a personalised design. The figure below provides information on the qualitative research approaches conducted and outcome(s) from each activity performed.

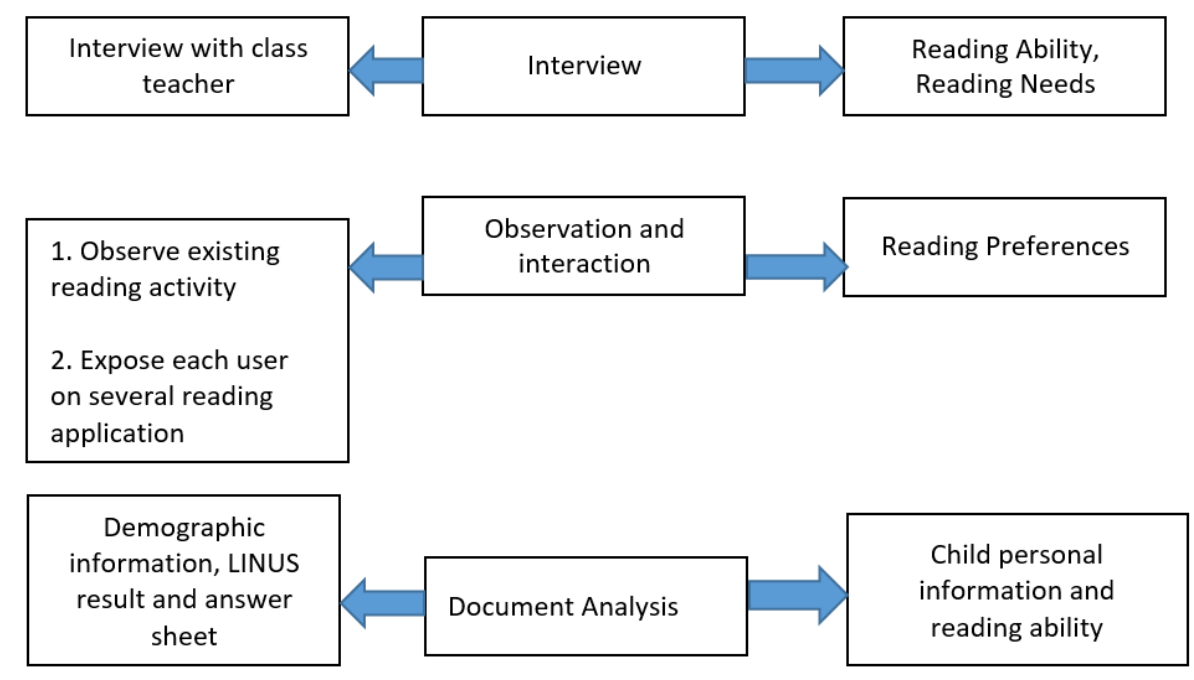

Fig. 3. Data Collection Process

Collecting Implicit information of slow learner through monitoring user reading activity: Implicit user information feedback approach focuses on the incorporation of implicit information in the construction of user profile. Gathering implicit information of slow learners while using the application does not require any intervention. The use of implicit information is important as it determines the changes in the personalisation feature embedded earlier which would take place using explicit information. Implicit information gathered from user behaviour while performing a reading activity determines the preferences and the needs of the user in the next usage of the reading application.

Capturing the implicit information from users is vital as it enriches the dynamic user profile information. Unlike the explicit information of the user which will not have 
an effect over time (static), the dynamic information provides useful information that will ensure that the user profile is updated. The combination of explicit and implicit information enables the developed user profiles to cover all beneficial information that can support the construction of a comprehensive user profile. The information on the implicit user feedback approach and based on the activity performed when the slow learner children using the reading application are provided for the personalisation purposes. However, in the construction of the user profile, the preliminary information while performing something similar (reading activity) is used as a foundation in collecting real implicit information of the user.

Table 1 summarises the implicit data collection technique which specifies how the implicit information is collected, type of implicit information, and category of information for user profiling, and also the relationship between the implicit information and personalisation.

Table 1. Implicit user feedback

\begin{tabular}{|l|l|l|}
\hline Collection Technique / Activity & Type of information Captured & $\begin{array}{l}\text { Category of information for user } \\
\text { profiling }\end{array}$ \\
\hline Login & User registration & User name / login info \\
\hline Test & Test on reading ability result & Reading ability \\
\hline $\begin{array}{l}\text { Native activity, Selection of pref- } \\
\text { ered colour, Selection of preferredd } \\
\text { reading buddy }\end{array}$ & $\begin{array}{l}\text { Browsing activity, Preferred back- } \\
\text { ground colour, Preferred reading } \\
\text { buddy }\end{array}$ & $\begin{array}{l}\text { Navigation information, colour } \\
\text { preferences, Reading companion }\end{array}$ \\
\hline End test & Test on reading ability result & Changes on Reading ability \\
\hline
\end{tabular}

\section{$4 \quad$ Findings}

The outcome from the data collection process is divided into four (4) criteria. The four criteria are

- Slow learner demographic information

- Slow learner prior knowledge in reading

- Slow learner reading needs

- Slow learner reading preferences. Brief information of the required explicit information and its relation to the design aspect before the development of user profile will be described in the next section.

\subsection{Slow learner raw information}

Slow learner demographic information: One of the elements in user profile development is by gathering rich information on the slow learner demographic information. Many previous studies have also considered demographic information in understanding user as part of user profile design and development. Examples include studies by [17];[14]; and [18]. Slow learner demographic information refers to the personal information of the slow learner children including age, gender, hobby, cartoon characters, reading style, and interesting topics in reading. The demographic 
information leads to a better design interface in personalisation. It is interesting to identify the personal traits of an individual in designing personalised reading materials so that personalisation can be developed according to their preference. For example, a cartoon character that a specific slow learner child prefers can be used as a reference in developing a preferred reading buddy in the personalised reading materials.

Slow learner prior knowledge: As described previously, one of the criteria in building the slow learner profile is understanding the existing knowledge of slow learners. Strong comprehension of the knowledge of the slow learners is the foundation that will assist the designer or even a school teacher to determine suitable or personalised reading content. Inability to provide necessary information based on each slow learner's ability will negatively influence the learning performance of the slow learner children as gathered from the analysis of the interview session conducted with one of the primary school teachers. Thus, it is required to understand the assessment of reading implemented at schools to understand the existing knowledge of the slow learner children. In Malaysian primary schools, the Ministry of Education has provided an effective tool to measure the ability of all primary school children in reading performance through the Literacy and Numeracy Screening (LINUS) programme. This assessment is gradually conducted to monitor children's performance from 7 years old to 9 years old. The reading ability for primary slow learner children is then categorised according to their reading performance. In brief, the LINUS programme is conducted to analyse children's progress in literacy learning. Table 2 indicates the LINUS assessment as determined by the LINUS constructs:

Table 2. Reading construct by LINUS assessment

\begin{tabular}{|c|l|}
\hline Construct & \multicolumn{1}{|c|}{ Description } \\
\hline K1 & Ability to sound and write vowels and consonant \\
\hline K2 & Ability to sound and write open syllable \\
\hline K3 & Ability to read and write open syllable \\
\hline K4 & Ability to sound and write close syllable \\
\hline K5 & Ability to read and write close syllable \\
\hline K6 & Ability to read and write words which contain 'ng' closed syllable \\
\hline K7 & Ability to read and write words which contains single vowel syllable \\
\hline K8 & Ability to read and write words which contains diphthong and cooperative vowel \\
\hline K9 & Ability to read and write words which contains digraph and cooperative consonant \\
\hline K10 & Ability to read and write word is with prefix and suffix \\
\hline K11 & Ability to read and write simple sentences \\
\hline K12 & Ability to read and understand stimulation material orally and in writing \\
\hline
\end{tabular}

The result in Table 3 describes the reading ability of the slow learner children based on a study conducted in a primary school in Malaysia. Among all 13 slow learners aged 9, the results indicated that 6 slow learner children are able to master word recognition, 2 can master the decoding stage in reading, and 5 were already mastering the semantic stage of reading which is related to the comprehension of the meaning of a word or sentence.Consequently, this study provides a feasible solution that can cater to the reading ability of these children categorised by word recognition, decoding, and semantic categories. However, due to the personalisation approaches 
that require us to observe the needs and preferences of the slow learner children, the identification process of the suitable aspect of the design does not stop once the existing knowledge of the slow learner children is identified. The next section explains the reading needs and reading preferences of the children as another consideration that should be catered in this study for the development of the personalised design content.

Slow Learner Reading Needs and Reading Preferences: Approaching slow learner children is different compared to how we communicate with other children at a similar age. The difference can be attributed to the characteristics of the slow learner children which require different approaches. The importance of handling slow learner children has been captured in several books which have provided several intervention strategies such as [19], [20] and [21]. Collecting information on reading needs and reading preferences of slow learners is an interesting part of this study. Not only the information determines the interactivity and the attractiveness of the user interface, the first process of finding the information is also a worthwhile experience. Finding information on reading needs and reading preferences of the slow learner children requires the researchers to be a part of the reading process in the primary school classroom. The slow learner children that were observed in this study are positioned in the remedial class in order to receive intensive practice on reading in the particular case study that was conducted. Slow learner children have poor self-image [22] and have low self-esteem, [23]. In order to communicate effectively with them during the interaction and observation session, a teaching and learning session was conducted and the researchers acted as new teachers. This requires the researchers to build a good reputation and establish trust with them. Although the observation session took longer, the results of the observation are very worthy to this study. All information on the reading needs and reading preferences with the one-to-one reading activity of each slow learner children have been successfully gathered. Several reading needs and preferences are depicted in Table 2.

Table 3. Matching criteria of personalization in reading

\begin{tabular}{|l|l|l|l|}
\hline \multicolumn{1}{|c|}{ Reading needs } & \multicolumn{1}{|c|}{ Design strategies } & Read Preferences & \multicolumn{1}{c|}{ Design Strategies } \\
\hline $\begin{array}{l}\text { Reading buddy or } \\
\text { teacher companion }\end{array}$ & $\begin{array}{l}\text { Provide animated and } \\
\text { preferred reading buddy }\end{array}$ & $\begin{array}{l}\text { Reading book based } \\
\text { on interest }\end{array}$ & $\begin{array}{l}\text { Develop book with identified } \\
\text { interest }\end{array}$ \\
\hline Repetition & Allow repetition & $\begin{array}{l}\text { Reading with or } \\
\text { without music }\end{array}$ & Enable / diable music \\
\hline Familiarized objects & $\begin{array}{l}\text { use familarized theme to } \\
\text { promote understanding }\end{array}$ & $\begin{array}{l}\text { Reading coloured } \\
\text { book }\end{array}$ & Coloured animation book \\
\hline $\begin{array}{l}\text { Read-aloud } \\
\text { mechanism }\end{array}$ & Provide narration & $\begin{array}{l}\text { Moving objects / } \\
\text { images }\end{array}$ & $\begin{array}{l}\text { Provide suistable images / } \\
\text { animation to avoid distraction in } \\
\text { reading }\end{array}$ \\
\hline
\end{tabular}

\subsection{User profile construction}

The user profile is not a new term. Apparently, a few years back, it has been used widely as a foundation for the implementation of personalized approach due to the importance of understanding a user [24]. User profile or user model is one feature that is important in personalization. The information stored in the user profile is essential 
to determine the different personalization effect on each individual user needs. In the development of personalized user Interface for slow learner children, the information of user profile is important to determine how the user interface is presented. In this particular study, the user profile was constructed by gathering explicit and implicit information of the users only. Due to the qualitative data collection technique implemented, as well as considering only reading activities are concerned, the user profile construction only focus on 4 important aspects that need to be considered in the design as proposed by [24] in his book entitled The Essential Guide to User Interface Design. All four aspects adapted in the construction of user profile in this study are:

- Knowledge/Experience

- User task and needs

- user psychological characteristics (motivation, expectation and cognitive style)

- user physical characteristics (name, age, cognitive processing, gender)

There are various ways of presenting user profiles such as keywords, semantic networks, or concepts, or association rules. In this particular study, the concept of user profile was used to identify related user profile features as proposed by [24]. Conceptlevel models of user interests are generally more powerful than keyword-level models. Compared to keywords, concept-level models allow a more accurate representation of interests. Concept user profiles are presented in the format of the node. The concept of user-describing profile describes using concept user profile that focuses on the in-depth understanding of a user for developing a personalised design. A good understanding of the user provides a clear explanation of the three important aspects of the user profile which are the existing knowledge of the user, reading needs, and reading preferences. In addition, the user profile also contains information on the personal explicit information of a particular user and the behavioural pattern which captures implicit information of a particular user while the user is performing a reading activity. The user profile is an important aspect of the personalisation tool. The type of information stored in the user profile is categorised into two (2) categories which are the static type of explicit information, and dynamic type of implicit information. All the necessary information is stored and the changes made by a particular user are recorded and updated to keep track of the user's reading pattern when using the application. Firstly, the data from the user are gathered and classified according to the reading ability based on the LINUS test result. The reading ability (RA) is used as a foundation for user profile classification. Grouping the children through similar RA would provide a solution for the children reading difficulties.

\section{Elements for content design:}

- Reading ability (RA)

- Reading needs (RN) are divided into 2 categories, one for the content design, another one for interface design

- Reading preferences

All information for content personalisation is related to reading ability, reading needs, and reading preferences. Only related information to the reading of slow learn- 
er children is considered as an element in the content design due to the understanding of slow learner difficulties in reading leads to better design. In this paper, only one user profile which falls into the $\mathrm{K} 12$ reading construct is presented as an example to provide a better understanding of the importance of developing the user profile for a better design.

Table 4. Focused categories of slow learner based on reading ability (K12 Reading Construct)

\begin{tabular}{|c|l|l|c|}
\hline Reading Construct & \multicolumn{1}{|c|}{$\begin{array}{c}\text { Categories of } \\
\text { Reading ability }\end{array}$} & \multicolumn{1}{|c|}{ Description on reading Ability } & No of slow Learner \\
\hline K2 & Phonology & Decoding & 1 \\
\hline K3 & Orthology & Word Recognition & 5 \\
\hline K4 & Phonology & Decoding & 1 \\
\hline K6 & Orthology & Word Recognition & 1 \\
\hline K11 & Semantic & Meaning & 2 \\
\hline K12 & Semantic & Meaning & 3 \\
\hline
\end{tabular}

In brief, there are three (3) user profiles created based on the identified slow learners' reading ability. Each user profile is designed to cater to each slow learner application. Three interface designs were also developed to cater to a specific user profile. However, due to the limitation in decryption capacity, only one user profile is presented in the form of graphical information as shown in Figure 5.

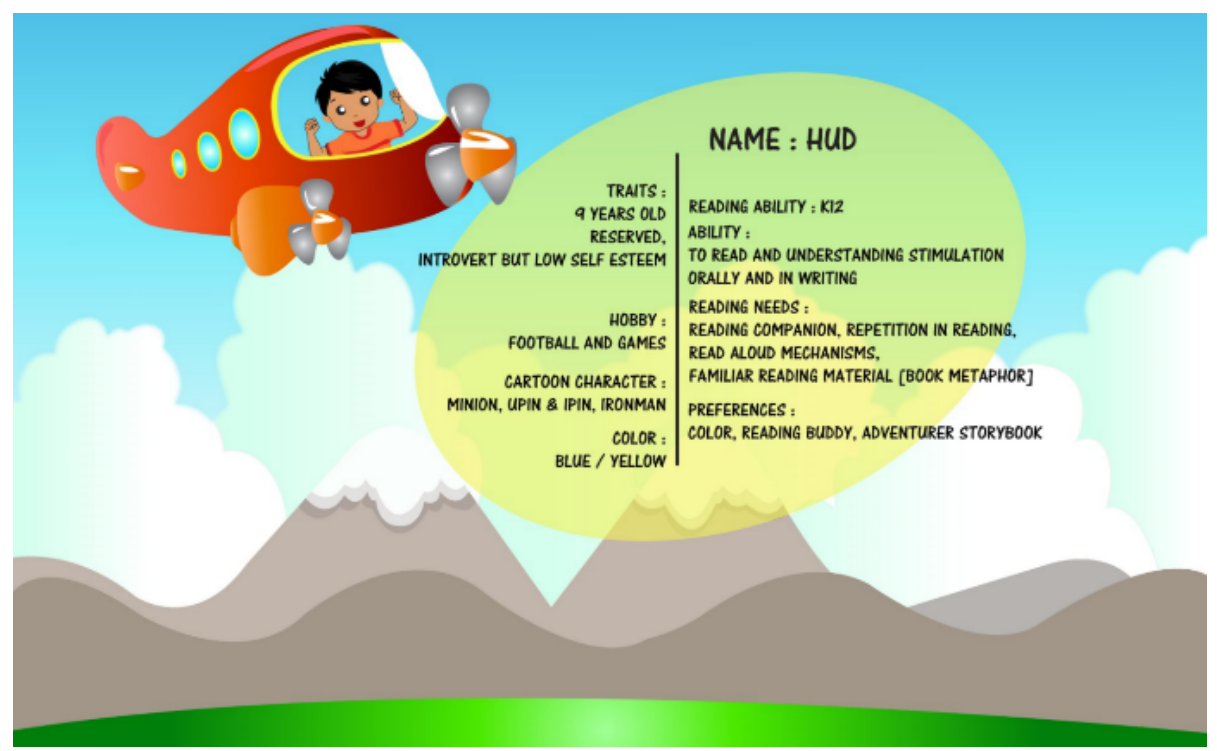

Fig. 4. User profile with $\mathrm{K} 12$ reading ability 


\section{Conclusion}

This study concludes that the development of personalisation approaches is a long process. The development requires a strong understanding of two important elements which are the specific user profile and personalisation design methods that are needed to be embedded as a solution. Understanding the user helps the designers to cater to specific problems or issues while understanding personalised design methods such as the development of the scenario helps the designers in understanding the method to develop a task or an activity in the development of artefact. Combining these two elements in the design process promises the possibility to provide workable personalisation as a design solution.

\section{Acknowledgement}

The authors would like to record our sincere thanks to the Universiti Teknologi MARA for the financial support. This research is supported under the funding of 600 IRMI/DANA 5/3/LESTARI (0137/2016)

\section{$7 \quad$ References}

[1] S. Cakula and M. Sedleniece, "Development of a personalized e-learning model using methods of ontology," Procedia Comput. Sci., vol. 26, no. December, pp. 113-120, 2013. https://doi.org/10.1016/j.procs.2013.12.011

[2] T. Yang, G. Hwang, and S. J. Yang, "Development of an Adaptive Learning System with Multiple Perspectives based on Students' Learning Styles and Cognitive Styles," J. Educ. Technol. Soc., vol. 16, no. 4, 2016.

[3] M. Gil, P. Giner, and V. Pelechano, "Personalization for unobtrusive service interaction," Pers. Ubiquitous Comput., vol. 16, no. 5, pp. 543-561, 2012. https://doi.org/10.1007/ s00779-011-0414-0

[4] Y. A. Rezaei, G. Heisenberg, and W. Heiden, "User Interface Design for Disabled People Under the Influence of Time, Efficiency and Costs," in Communications in Computer and Information Science, 2014, vol. 435 PART I, pp. 197-202. https://doi.org/10.1007/978-3$\underline{319-07854-0 \quad 35}$

[5] T. H. Wang, "Developing an assessment-centered e-Learning system for improving student learning effectiveness,” Comput. Educ., vol. 73, pp. 189-203, 2014. https://doi.org/ $\underline{10.1016 / \text { i.compedu.2013.12.002 }}$

[6] A. G. Hwang, H. Sung, C. Hung, and I. Huang, "A Learning Style Perspective to Investigate the Necessity of Developing Adaptive Learning Systems," J. Technol. Soc., vol. 16, no. 2, 2016.

[7] C. Chen, "Personalized Intelligent Mobile Learning System for Supporting Effective English Learning Published by: International Forum of Educational Technology \& Society Personalized Intelligent Mobile Learni,” Int. Forum Educ. Technol. Soc., vol. 11, no. 3, 2017.

[8] J. M. Carroll, Making use: scenario-based design of human-computer interactions, vol. 48. 2000. 
[9] K. Wu, Y. Tang, and C. Tsai, "Graphical interface design for children seeking information in a digital library," Vis. Eng., vol. 2, no. 1, p. 5, 2014.

[10] K. Moffatt, J. David, and R. M. Baecker, "Reading, Laughing and Connecting with Young Children," Springer-Verlag London, pp. 173-193, 2013.

[11] C. Walkington and M. Sherman, "Using adaptive learning technologies to personalize instruction: The impact of interest-based scenarios on performance in algebra," J. Educ. Psychol., vol. v105, no. 4, pp. 932-945, 2013.

[12] A. Gauch, Susan; Speretta, Mirco; Chandramouli,Aravind; Micarelli, "User Profiles for Personalized Information Access," Adapt. Web, vol. 4321, pp. 54-89, 2007. https://doi.org/10.1007/978-3-540-72079-9 2

[13] S. Kanoje, S. Girase, and D. Mukhopadhyay, "User Profiling Trends, Techniques and Applications,” Int. J. Adv. Found. Res. Comput., vol. 1, no. 11, pp. 2348-4853, 2014.

[14] G. Jawaheer, M. Szomszor, and P. Kostkova, "Comparison of implicit and explicit feedback from an online music recommendation service," Proc. 1st Int. Work. Inf. Heterog. Fusion Recomm. Syst. - HetRec '10, pp. 47-51, 2010. https://doi.org/10.1145/ $\underline{1869446.1869453}$

[15] D. Godoy and A. Amandi, "User profiling in personal information agents: A survey," Knowl. Eng. Rev., vol. 20, no. 4, pp. 329-362, 2005.

[16] Ahmed Altaboli, "Investigating the Effects of Font Styles on Perceived Visual Aesthtics of Website Interface Design," LNCS 8004 - Human-Computer Interact. Hum. centered Des. approaches, methods, tools Environ., vol. 1, no. July, 2013. https://doi.org/10.1007/978-3642-39232-0_59

[17] K. L. Mcclarty and M. N. Gaertner, "Measuring Mastery: Best Practices for Assessment in Competency-Based Education," no. April, p. 16 p., 2015.

[18] L. Wawryk-Epp, G. Harrison, and B. Prentice, Teaching Students with Reading Difficulties and Disabilities: A Guide to Educators. Saskatchewan Learning, 2004.

[19] A. G. K. Hugh W. Catts, The Connections Between Language and Reading Disabilities. London: Lawrence Erlbaum Associates, 2005.

[20] A. Druin, Mobile Technology for Children:Designing for Interaction and Learning. Amsterdam: Morgan Kaufman Publishers, 2009.

[21] Y. S. Al-hashmi, "Slow Learners: How are they Identified and Supported?," English, 2008.

[22] B. Wawryk-Epp, Lynne; Harrison, Gina; Prentice, Teaching Students with Reading Difficulties and Disabilities: A Guide for Educator. 2004.

[23] B. Saleena and S. K. Srivatsa, "Using concept similarity in cross ontology for adaptive eLearning systems," J. King Saud Univ. - Comput. Inf. Sci., vol. 27, no. 1, pp. 1-12, 2015. https://doi.org/10.1016/j.jksuci.2014.03.007

\section{Authors}

Dr Wan Adilah Wan Adnan has over 30 years of experience in academic sector. Currently she is an Associate Professor at the Faculty of Computer and Mathematical Sciences, Universiti Teknologi MARA (UiTM). She is the Internal Audit committee of the faculty. Wan Adilah is also a panel assessor of the Malaysia Qualifying Agency (MQA), a statutory body to accredit academic programs since year 2001. Wan is also an external accessor for masters programs at the Madinah International University, Malaysia. Her research interest is in HCI focusing on usability and user experience evaluation, personalization as well as community informatics and in curriculum de- 
sign and development. Her consultancy includes conducting expert usability evaluation on MYJOBMALAYSIA 2.0 for the Ministry of Human Resource Malaysia.

Dr Natrah Abdullah@ Dollah is currently a Senior lecturer at Faculty of Computer and Mathematical Sciences,Universiti Teknologi MARA (UiTM). She received her Ph.D in Information technology from the University of Teknologi MARA in 2012.Her research interests are in Human Computer Interaction: Personalization and Customization, User Interface Design, User Experience Evaluation, Usability Testing, Information Representation.

Marzita Mansor is a lecturer at Faculty of Art, Computing and Creative Industry (FSKIK), Universiti Pendidikan Sultan Idris (UPSI). Currently she is a Ph.D candidate at Universiti Teknologi MARA (UiTM). Her research interest are in in HumanComputer Interaction (HCI) with particular interest is in interaction design for users in various background

Article submitted 2019-04-23. Resubmitted 2019-06-04. Final acceptance 2019-06-04. Final version published as submitted by the authors. 